\title{
O processo verbal ler e o seu processamento numa perspetiva psicolinguística
}

\author{
The verbal languaging process reading and its processing from a psycholinguistic perspective
}

\author{
El proceso verbal leer y su procesamiento desde una perspectiva psicolingüística
}

Maria da Graça Pinto $\odot$

Faculdade de Letras da Universidade do Porto, Porto, Portugal.

\begin{abstract}
RESUMO
Traduz este texto a preocupação de fazer chegar ao leitor uma abordagem aos processos verbais - ouvir, falar, ler e escrever - em que ressalte a sua complementaridade e não simplesmente a especificidade de cada um. Para o efeito, advoga-se que a sua análise radique em uma perspetiva, preferencialmente psicolinguística, que explique o que se passa no plano do processamento desses processos, com o intuito de descobrir nesse percurso, que deve ir até à sua raiz, o que realmente os caracteriza. Conquanto os quatro processos sejam todos convocados nos momentos achados oportunos, dois deles receberam uma atenção especial: ouvir e ler. Explica-se esta escolha por serem ambos próximos em muitos aspetos, sobretudo em alguns que ocultam injustamente o seu árduo labor latente, injustiça que se tentou combater ao longo do texto. Ao processo ler conferiu-se uma especial atenção à medida que a escrita a ia solicitando e não somente por força de qualquer intenção prévia. Estiveram, contudo, sempre por perto os restantes processos, porque contribuem, em graus naturalmente distintos, para a instalação e posterior desenvolvimento da leitura. O objetivo principal deste texto reside em incentivar uma problematização firmada na Psicolinguística de qualquer temática inerente ao seu campo de ação.
\end{abstract}

Palavras-chave: Psicolinguística. Problematização. Processos verbais. Ler.

\begin{abstract}
This text aims to assert an approach to the verbal languaging processes - listening, speaking, reading and writing - in which their complementarity is highlighted, rather than their individual specificity. It is argued that this analysis should be based on a psycholinguistic perspective, which explains what happens during their processing from beginning to end, in order to find out what exactly characterises them. Even though all four processes will be referred to, two of them will be focused on - listening and reading. This choice is justified by the fact that they share multiple aspects, particularly the latent hard labour which some unjustly hide. This injustice is counteracted throughout the text. Special attention has been given to the process reading due to its constant evocation writing imposed, and not only due to previous intention. The other processes will be present as they contribute, in different degrees, to the setting and later development of reading. The main objective of this text is to encourage a problematisation from the psycholinguistic perspective of any topic related to its field of action.
\end{abstract}

Keywords: Psycholinguistics. Problematisation. Languaging verbal processes. Reading.

\section{RESUMEN}

Traduce este texto la preocupación de hacer llegar al lector una aproximación a los procesos verbales - oír, hablar, leer y escribir - en la que se resalte su complemetariedad y no sencillamente la especificidad de cada uno. A tal efecto, se aboga por que su anáisis radique en una perspectiva preferentemente psicolingüistica, que explique lo que pasa en el plano del procesamiento de esos procesos, con la intención de descubrir en ese trayecto, que debe ir hasta su raíz, lo que realmente los caracteriza. Aunque los cuatro procesos se invocan en los momentos considerados oportunos, dos de ellos han recibido una atención especial: oír y leer. Se explica esta elección porque ambos están próximos en muchos aspectos, sobre todo en algunos que ocultan injustamente su ardua labor latente, injusticia que se ha intentado combatir a lo largo del texto. Al proceso leer se le ha conferido una especial atención a medida que la expresión escrita la iba solicitando y no solameente por fuerza de cualquier intención previa. Han estado, 
con todo, siempre cerca los restantes procesos, porque contribuyen, en grados naturalmente distintos, a la creación y posterior desarrollo de la lectura. El objetivo principal de este texto reside en incentivar una problematización afirmada en la psicolingüistica de cualquier temática inherente a su campo de acción.

Palabras clave: Psicolingüística. Problematización. Procesos verbales. Ler.

\section{Apontamento inicial}

De entre os quatro processos verbais (ouvir, falar, ler e escrever), os organizadores do presente número da revista Letras de Hoje elegeram a leitura como tema principal, não deixando, porém, de fazer referência à sua estreita ligação à linguagem, no que se reporta ao processamento, e à escrita, mercê da cumplicidade entre ambas as habilidades, facilmente equiparáveis às duas faces de uma moeda.

Na sinopse basicamente redigida com a finalidade de orientar quem pretender submeter trabalhos, apelam ainda os relatores para abordagens da ordem da Psicolinguística e das suas interfaces, ou seja, na opinião dos mesmos, "da Psicologia, das Neurociências, da Fonoaudiologia, da Educação, assim como das Tecnologias", por conta do que essas áreas disciplinares podem concorrer para um conhecimento mais minucioso da leitura nos ramos da investigação e do ensino. Observada assim a Psicolinguística, não se pode descartar que se esteja perante uma "multidisciplinarily connected science" (ciência conectada multidisciplinarmente), tal como a designou Slama-Cazacu (2007), e não simplesmente diante de um terreno interdisciplinar, como poderá advir, em um primeiro momento, do termo "psicolinguística". É legítimo por isso aduzir, na trilha dos organizadores deste número da revista, que um "objeto" estudado através de diferentes lentes sai mais enriquecido porque dele se retiram vários modos de o observar, o que lhe confere uma visão mais completa e aprofundada. Notava já a saudosa Professora Hermina Sinclair, em uma das suas conversas informais sempre tão enriquecedoras, que os especialistas em Psicolinguística tinham duas saídas possíveis: a atuação em meio clínico e no campo pedagógico. Em boa verdade, seria mesmo de acrescentar que um profissional da área do ensino, investigador ou professor, que detenha experiência clínica se encontrará mais bem capacitado para exercer o seu ofício, posto que poderá quer encontrar com mais facilidade explicação para os desempenhos que vier a verificar no seu públicoalvo, quer, se o quadro o exigir, avançar propostas para a sua reeducação. Possuir as duas experiências (clínica e educativa) mune assim de uma mais-valia quem investiga ou ensina os processos verbais supracitados, porquanto implica, sem reticências, que passará a deter um saber mais amplo e um discernimento mais fino nas diferentes situações em que esses processos ocorram. A conjugação de perspetivas decorrentes de várias disciplinas é já tida como basilar por Slama-Cazacu, quando informa, em um livro seu sobre a Psicolinguística aplicada ao ensino de línguas, traduzido para o português do Brasil por Leonor Scliar-Cabral, que a Psicolinguística "propriamente dita", ao perscrutar "a situação da comunicação real, os fatos reais [...] [e] as determinantes sociais que aí operam", (SLAMA-CAZACU, 1979, p.62) assume, conforme prossegue, um cariz "sócio-psicolinguístico", o que, seguindo a mesma fonte, a distingue da psicologia social e da psicologia geral da linguagem pelo enfoque que confere ao objeto de estudo também no plano linguístico,

É este desafio multidisciplinar, retomando a terminologia de Slama-Cazacu, que a chamada de trabalhos para este número de Letras de Hoje lança a quem nele quiser colaborar, demandando sem qualquer dúvida um empenhamento questionador, e não somente resolutivo, que enriquecerá com certeza um leitor deveras interessado na habilidade leitura e seu enquadramento.

Será objetivo do presente texto contribuir para outorgar ao leitor uma panorâmica alargada do ato de ler que lhe propicie, na melhor das hipóteses, um olhar distanciado daquele que já detinha dessa habilidade.

\section{Os processos verbais de primeira ordem e de segunda ordem}

A partir do momento em que é selecionada a leitura como tema deste número de "Letras de Hoje", convém especificar o seu estatuto nos processos verbais tradicionalmente designados de segunda ordem. Lembra Emig (1977, p. 122) que o que diferencia os processos de primeira ordem - falar e ouvir - dos de segunda ordem - ler e escrever - apoia-se no facto de os primeiros não estarem sujeitos para a sua aquisição a uma instrução formal ou sistemática, e de os de segunda ordem serem aprendidos por meio desse tipo de instrução.

Associar, na ausência de qualquer equacionamento, a aquisição aos processos de primeira ordem e a aprendizagem aos de segunda ordem pode levantar tantas interrogações quanto aliar, na falta de uma ponderação 
cuidada, atividades online e offline a habilidades verbais recetivas - ouvir e ler - e produtivas - falar e escrever -, respetivamente (RAMÍREZ GÓMEZ, 2016). Em suma, as dimensões dicotómicas avançadas, não obstante o seu cunho diverso, não deveriam ser apreendidas como categorias mutuamente exclusivas, mas sim, entre outros, como funcionalmente complementares.

A respeito de aquisição e aprendizagem e de ouvir e ler, algumas observações serão avançadas a fim de carrear informações passíveis de dotar o leitor de meios que não o deixem indiferente. Não se enseja, portanto, que, após a leitura do presente texto, este se sinta apenas mais conhecedor da matéria em análise, apesar de ser isso o que um autor em regra ambiciona; espera-se, também, que ele possa reagir por meio de uma atitude crítica, obrigatoriamente bem fundamentada, passando, por exemplo, a escrito, de preferência através de um artigo, o que do que leu lhe motivou alguma controvérsia.

\section{A aquisição e a aprendizagem}

No atinente à aquisição $v s$. aprendizagem, terá de ficar claro que o oral, um dos processos verbais de primeira ordem, não sujeitos a instrução formal e sistemática, de acordo com o relatado, também pode e até deve ser aprendido (GIROLAMI-BOULINIER, 1993), contribuindo assim, nas crianças mais novas, para uma entrada no mundo da escrita com mais distância relativamente à linguagem (PINTO, 2017a), e, nos mais velhos, para um maior à-vontade e precisão nas suas apresentações mediadas pela fala. Odisho (2007, p.10) propõe, para quebrar possíveis leituras radicais dos dois processos, dois verbos compostos: o primeiro verbo, "acquire-learn" ("adquirir-aprender"), aplicável mais apropriadamente às crianças e o segundo, "learnacquire" ("aprender-adquirir"), aos adultos. Não causa, de resto, estranheza que os termos "aprender" e "adquirir" oscilem nos textos dos mais variados autores, sobretudo dos que se dedicam ao ensino de línguas segundas, matéria em que são exibidas e discutidas com mais respaldo teórico a aquisição e a aprendizagem. Por certo, dos dois verbos escapa a quem deles se vale um domínio do sentido apropriado de cada um, em conformidade com as circunstâncias que viabilizem o recurso a cada um devidamente diferenciado. Ellis (1994), na sua obra premiada, com um título decerto não inopinado, ou seja, The study of second language acquisition, explica justamente a sua opção pelo emprego indistinto de aquisição e aprendizagem - decidindo-se pelo uso de "acquisition", visível de imediato no título transcrito -, termos que escreverá, em contrapartida, entre aspas, sempre que os quiser distinguir nos seus escritos. $\mathrm{Na}$ media em que se trata, nestes casos, de uma segunda língua, revela-se nítida a aproximação do ensino desse objeto de estudo dos processos verbais de segunda ordem (ler e escrever), todos eles, em consonância com o exibido, sujeitos a uma instrução formal e sistemática. Merecem, assim, um tratamento especialmente crítico os termos aquisição e aprendizagem em determinadas situações e tendo em vista certas matérias.

Em uma ótica psicolinguística, justifica-se destacar o papel singular que a aquisição relativa à linguagem assume nos seus primórdios e talvez não só. Com efeito, a linguagem como objeto de aquisição tem um estatuto único, na medida em que tanto constitui um objeto deveras complexo que a criança também tem de ir conquistando, para além dos restantes objetos que compõem a realidade que a cerca, como serve de meio para representar o que ela vai ${ }^{1}$ conhecendo à sua volta por força da capacidade de simbolização que caracteriza essa habilidade/faculdade (SINCLAIR, 1974). Essa dupla função outorga-lhe uma peculiaridade que não deve ser de forma alguma escamoteada por quem se dedica ao estudo da linguagem, uma vez que seria muito empobrecedor não ver nela o que a torna ímpar como objeto de conquista: uma conquista dela própria e dos outros objetos através da sua mediação verbal.

\section{Ouvir e ler: algumas notas acerca da sua caracterização}

Quanto a ouvir e ler, embora processos verbais denominados recetivos, não podem andar, cegamente, agregados a offline, sobretudo se ao modo offline se acoplar a ideia de passividade. Ler e ouvir, embora processos verbais distintos em função das modalidades de uso da língua de que se servem (MARCUSCHI, 2001), têm em comum extrair a informação e assimilar a que é essencial e pertinente da acessória, atividades que postulam que o sujeito opere no modo online (ELKONIN, 1984).

$\mathrm{Na}$ senda de algumas críticas feitas à distinção entre funções recetivas e produtivas dos processos verbais aludidos, Emig (1977) previne precisamente para o perigo de os processos verbais ditos recetivos poderem vir a ganhar conotações de passividade e de os produtivos, em compensação, sugerirem vitalidade e construção. Note-se que o ouvir está a serviço da monitorização do falar e que o ler serve o mesmo fim na tarefa de escrever, já para não fazer alusão ao papel indispensável da leitura no processo de revisão da escrita. É de toda a legitimidade adir que a estreita ligação entre a leitura e a escrita não se encontra somente presente na aprendizagem inicial. Ela terá de ser uma constante ao longo da vida de quem

\footnotetext{
1 Ver também Luria, 1988.
} 
escreve, muito em particular quando é atribuído um papel crucial à revisão da escrita, independentemente da forma que esta possa tomar - normativa e/ou comunicacional (BISAILLON, 2007) - e de quem a possa exercer (autor ou revisor profissional com um mandado específico). ${ }^{2}$

Uma outra diferença focada por Emig, em 1977, e que se afigura mais ajustada a falar e a escrever, por um lado, e a ouvir e a ler, por outro, encontra-se estampada no que existe nesses processos em matéria de criar (dar existência) e de originar (fazer nascer). O processo de (re)criar, mas não de originar, estará presente no ouvir e no ler, e o processo de originar e criar no falar e no escrever. Na realidade, dá-se corpo de forma não gráfica, ou seja, sonora, sempre que se fala, e gráfica, quando se escreve, aos constructos verbais que se originam e (que seguidamente) se criam; por sua vez, cada vez que se ouve e se lê, cria-se ou recria-se, mas não se origina, um constructo verbal em forma não gráfica ou gráfica, respetivamente (EMIG, 1977), dado que o dito constructo foi um produto originado previamente sob forma oral ou escrita por terceiros ou então pelo próprio, na hipótese de esse se estar a ouvir em gravação ou a ler o que escreveu.

Urge perguntar se é a diferença entre originar e criar que está também na base da diferenciação entre os intitulados processos verbais online e offline. Será, nas circunstâncias, o ato de originar - de encontrar, de resgatar, de recuperar - o que se enseja dizer ou escrever que justifica a designação online?

Que se passará, então, com criar ou recriar e também com todo o processamento que exigem as tarefas de ouvir e ler?

Recorde-se, no que se reporta à leitura, como o estudo do seu processamento, tomando por base uma análise psicolinguística de erros cometidos por doentes afásicos (MARSHALL; NEWCOMBE, 1973), concorreu para uma nova tipologia da dislexia (de superfície, profunda e fonológica) a par da proposta de modelos de processamento de leitura de via dupla e tripla (MORTON; PATTERSON, 1980; TEMPLE, 1985a). Não sem surpresa contribuíram também esses modelos para que se tivessem dado francos avanços no domínio terapêutico (HOWARD; HATFIELD, 1987), já que revelaram que nem todas as vias de leitura se encontravam afetadas no mesmo grau e que se podia recorrer às não atingidas para reabilitar a deficiência manifestada pelos pacientes com perturbações dessa categoria. Repare-se que, nesta ótica, o termo "dislexia" substitui o termo "alexia", por se passar a considerar que os distúrbios de leitura não deviam ser vistos de modo irreversível em todos os doentes que apresentavam problemas nessa habilidade, consoante poderia fazer depreender o prefixo "a-", com o

\footnotetext{
2 Ver Pinto, 2017b.
}

significado de negação, falta de, ou ausência de. Revelam bem os desempenhos encontrados na tipologia de dislexias aduzida que nenhum leitor está completamente offline, antes se encontra em um estado de (re)criação por diferentes vias do material gráfico, que tem de converter em sonoro, independentemente de ser audível ou não. Importará observar que o termo "dislexia" é aqui usado deliberadamente para designar uma perda adquirida da capacidade de ler motivada por lesão cerebral e não uma perturbação da ordem do desenvolvimento, a despeito de também ser possível atribuir essa classificação a esta segunda categoria de afetação da leitura (TEMPLE, 1984; 1985b).

\section{A transcodificação/(re)criação na leitura}

Em uma terminologia análoga à de Emig (1977), Elkonin (1988, p. 396, grifos do autor) desenvolve a sua conceção de leitura em fases iniciais e adita que esta se define "como o processo de recrear a forma sonora das palavras de acordo com o seu modelo gráfico"3, posto que, para que a criança leia, é esperado que ela encontre na sua linguagem (oral) um correspondente sonoro do que lhe apresentam por escrito. Prova "visível" desse comportamento está patente, tanto na criança, quando esta, em etapas iniciais, lê em voz alta, como nas pessoas com baixa escolaridade ou com pouca prática da leitura que, quando leem, acompanham a leitura de movimentos articulatórios, tornando não raramente audível o que leem.

Pode pensar-se que terá sido esse entendimento que esteve subjacente à resposta que uma criança de 5 anos e 10 meses deu quando lhe perguntaram o que era para ela ler. E a resposta foi a seguinte: "É olhar e depois falar para dizer."

Percebe-se que essa criança vê a concretização da leitura através da fala, o que não se afasta da proposta de transcodificação inicial apresentada por Elkonin e que ainda se manifesta mais patente no excerto abaixo de sua autoria.

A (re)criação da sonoridade das palavras pode equiparar-se à decifração, à descodificação, à leituraperceção: primeiro passo para alcançar o que importa em matéria de leitura, ou seja, compreender o que se encontra escrito. Esta caminhada na aprendizagem da leitura também consta com grande nitidez na seguinte passagem de Elkonin (1988, p. 396):

A leitura realiza-se, sobretudo, com base na re-criação da forma sonora da fala. Por certo, este processo desenvolve-se gradualmente a partir da leitura oral expandida, através de uma série de estádios, num

\footnotetext{
Do original: as the process of re-creating the sound form of words
} according to their graphic model, 
processo reduzido e abreviado de leitura silenciosa e rápida, em que a re-criação da forma sonora pelo leitor já não é evidente. Porém, tudo o que é exigido, mesmo a alguém que lê bem, é encontrar uma palavra difícil ou um texto difícil para ler imediatamente de forma a voltar à sua forma oral - se não for em voz alta, se não for num sussurro, pelo menos na sua forma encoberta, i.e., na sua forma primária primordial - a forma de recriar a forma sonora de palavras e frases ${ }^{4}$.

\section{A leitura-compreensão e os seus pressupostos}

Acerca da leitura-compreensão, constata-se que essa não é esquecida ou marginalizada por Elkonin (1988, p.396). O autor adverte a esse propósito que "sem a recriação da forma sonora de uma palavra, é impossível compreender o que é lido". ${ }^{5}$ Alega o autor que ler significa compreender, embora para isso, no seu parecer, se tenha de passar pela conversão do objeto gráfico em sonoro audível ou não -, isto é: sem a (re)criação da forma sonora de uma palavra não é possível compreender o que é lido. A compreensão reivindica, pois, a automatização de uma etapa inicial no processo da leitura, que se identifica, dependendo das perspetivas, com a recriação sonora das palavras, com a sua decifração, com a sua descodificação, com a sua leitura-perceção.

Não causa surpresa que, a este respeito, Stanovich (2000) proponha o estabelecimento de uma correlação entre a fluência na leitura e o grau de automatismo que o leitor atinge a nível dos processos mais próximos do estímulo a fim de que a sua atenção o encaminhe para a compreensão. Escreve, então, esse autor:

Um processo considera-se automático quando pode realizar-se sem que a atenção the seja dirigida $[\ldots]$ Provavelmente um leitor desenvolve fluência tornando automáticos certos processos de nível inferior como a identificação da letra e da palavra de forma que a atenção se foque em funções mais elevadas como a compreensão (STANOVICH, 2000, p. 14). ${ }^{6}$

\footnotetext{
4 Do original: Reading takes place, above all, on the basis of re-creating the sound form of speech. Of course, this process develops gradually from expanded oral reading, through a series of stages, into a curtailed and abbreviated process of silent and rapid reading, in which the reader's re-creation of the sound form is no longer overt. However, all that is required, even for someone who reads well, is to encounter a difficult word or a difficult text for reading immediately to return to its oral form - if not aloud, if not in a whisper, nevertheless to its covert form, i.e., its primordial primary form - the form of re-creating the sound form of words and sentences.

5 Do original: without the re-creation of the sound form of a word, it is impossible to comprehend what is read.

6 Do original: A process is considered to be automatic when it can take place without the attention being directed to it [...] Presumably a reader develops fluency by automating certain low-level processes such as letter and word identification so that the attention can be allocated to higherlevel functions such as comprehension (STANOVICH, 2000, p. 14).
}

O fragmento transcrito pode levar a pensar nos modelos ascendente e descendente, tantas vezes convocados em matéria do processamento da leitura, o que justifica que, neste preciso momento, se recomende uma leitura crítica dos mesmos, apelando, em particular, para o modelo interativo-compensatório, que ajuda a aprofundar a complexidade do processamento da leitura e a observar as possibilidades de relacionamento entre os vários recursos de conhecimento passíveis de intervir no ato de ler, independentemente da sua localização em um processamento de tipo hierárquico como o que está em questão. $^{7}$

O relacionamento na citação supra da automatização de um processo, neste caso da leitura-decifração, com a fluência de leitura também pode sugerir que se capta na habilidade leitura o que se passa na fala. Goldman Eisler (1968), retomando Hughlings Jackson, considera, no que concerne ao discurso oral, os processos subconscientes/ automáticos e os conscientes/voluntários.

$\mathrm{Na}$ hipótese de ser possível transferir o que se passa na fala para a leitura, bem como de se poder asseverar que ambos os processos verbais são próximos, o excerto seguinte é deveras eloquente por mostrar o que distingue um ato automático/involuntário, que com a prática se converte em hábito, de um ato voluntário, que assenta em um ato de decisão:

\section{A diferença reside no facto de num caso o enunciado ser o resultado de um ato de decisão, enquanto no caso de um enunciado involuntário, automático se lida com sequências verbais que com a prática se tornaram hábitos verbais associados a uma situação concreta particular (GOLDMAN EISLER, 1968, p. 29). ${ }^{8}$}

Vem ainda a terreiro, na sequência das palavras citadas, evidenciar como uma prática continuada por meio de atos involuntários/automáticos se pode converter em um hábito que não só contribui para a libertação de meios necessários à atuação em etapas que demandem atos de decisão voluntários, mas também para o aprimoramento da habilidade em exercício. Simboliza este "movimento" o sobejamente conhecido "efeito Mateus" - "rich-get-richer" e "poor-get-poorer effects" ("efeitos pobre-torna-se-mais pobre" e "rico-torna-semais rico") (STANOVICH, 1986, p. 382), que toma por base a conhecida parábola dos talentos, aplicável em uma leitura não teológica, mas sim secular, também à leitura.

\footnotetext{
7 Ver: Stanovich, 2000.

8 Do original: The difference is that in the one case the utterance is the result of an act of decision, while in the case of involuntary, automatic utterance we deal with verbal sequences which through practice have become verbal habits associated with a particular concrete situation (GOLDMAN EISLER, 1968, p.29).
} 
E o confronto com o fenómeno da dicotomia reaparece de novo, desta vez com as dimensões "automático" e "voluntário". O apelo a alguma prudência no uso exclusivo de cada uma dessas dimensões tem toda a pertinência, uma vez que, dependendo das situações, é bem possível que os atos supostamente automáticos necessitem de recorrer a atos voluntários para que o desempenho em causa seja o que se augura. A complementaridade funcional está, pois, de novo à prova. Dela já se tinha dado nota e encontra-se bem clara no trecho transcrito da página 396 de Elkonin (1988).

Essa complementaridade dimensional pode ainda constatar-se no seguinte trecho do mesmo autor em torno da aprendizagem da leitura:

[...] o processo de aprender a ler tem de ser compreendido como a reconstrução por parte do aprendiz do controle da fala e da sua conversão de um processo automático num voluntário, regulado conscientemente com a subsequente automatização (ELKONIN, 1988, p. 399, grifo do autor). ${ }^{9}$

A ideia de que ler é compreender não emana naturalmente de um único autor. Andrée GirolamiBoulinier tinha bem presente essa conceção da leitura, como se pode reparar na seguinte passagem: "Ler não é titubear, mas é compreender ... e compreender evidentemente frases" (GIROLAMI-BOULINIER, 1993, p. 42). ${ }^{10}$

A compreensão, apoiada em grande parte no que está latente no material gráfico que serve de ponto de arranque da leitura, nas entrelinhas, conforme se costuma dizer, ecoa de uma forma muito intensa no conhecido pensamento que se transcreve de Agostinho da Silva ${ }^{11}$ que revela como dominar unicamente a decifração não basta para transpor a entrada no mundo da escrita. Segue-se, então, esse pensamento tão forte em matéria do que se deve entender por ler com proficiência: "Lerás bem quando leres o que não existe entre uma página e outra da mesma folha".

Terá de se acrescentar que muito tem de ser investido para que se possa obter a bagagem necessária para "conversar" com o que está para lá da dita entrada, ou seja, o miolo desse mundo da escrita, pleno de fantasia, mas também de conhecimento para a vida, e que pode ser divisado quer como fonte de prazer, quer como meio para satisfazer as nossas necessidades/obrigações.

\footnotetext{
9 Do original: [...] the learning to read process must be understood as the learner's reconstruction of the control of speaking and its conversion from an automatic to a voluntary, consciously regulated process with subsequent automation.

${ }^{10}$ Do original: Lire, ce n'est pas ânonner, mais c'est compreendre...et comprendre des phrases évidemment.

${ }^{11}$ Disponível em: https://citacoes.in/autores/agostinho-da-silva/?o=popular \&page $=12$. Acesso em: 12 jun. 2019.
}

Todo esse procedimento, que tem início na decifração e que visa a compreensão, reforça a ideia de que ler não é de forma alguma uma atividade em que o agente em jogo se encontra offline.

Recorrendo ainda a Girolami-Boulinier (1988), pode comprovar-se que o modo online está sem dúvida ativo na leitura quando esta autora assinala que a leitura só se encontra adquirida quando a criança já consegue ler interiormente sem pronunciar, ou seja, quando a criança "encontra na leitura uma materialização da linguagem interior" (1988, p. 24, grifo do autor). ${ }^{12}$ Prossegue a autora explicando que a criança deve conhecer e reconhecer o material para que sejam imediatas quer a identificação, no plano da operação intelectual, quer a emissão, no plano da realização motora (audível), no caso da leitura em voz alta. Colocou-se audível entre parênteses porque tudo leva a crer que se registam igualmente movimentos associados à articulação quando se lê em silêncio. Estudos de eletromiografia ajudariam a fundamentar o que foi sugerido, não obstante já poderem existir esses dados, que aqui não são convocados por falta de acesso a essa documentação. O que foi avançado não deve, todavia, estar muito afastado do que se passa na realidade, em virtude do que se lê em Luria e Tsvetkova (1968, p. 194) acerca da fala:
Sabe-se bem que qualquer intenção fornece uma preparação preliminar para a ação, e que é necessário um CONJUNTO preliminar para que a acão seja um sucesso. Nos casos de preparação para a atividade verbal, pode ver-se um desses conjuntos preliminares espelhado numa mudança do eletromiograma do trato vocal. ${ }^{13}$

De resto, em uma perspetiva psicolinguística, qualquer atividade verbal obedece a um processamento e, como tal, o seu agente só aparentemente pode parecer que se encontra inativo ou que está em modo offline. $\mathrm{O}$ ouvinte/leitor está de tal maneira online nas habilidades ditas recetivas que, ou porque não ouviu com clareza, ou porque leu algo que lhe é desconhecido, necessita por vezes de operar restauros com base essencialmente no contexto, já para não apelar a toda a atividade neurocognitiva e fisiológica que tais tarefas implicam, bem como ao papel que assume nessas circunstâncias a linguagem interior.

\footnotetext{
${ }_{12}$ Do original: retrouve dans la lecture une matérialisation du langage intérieur.

${ }^{13}$ Do original: It is well known that every intention provides preliminary preparation for action, and that a preliminary SET is needed to make the action successful. In cases of preparation for verbal activity, such a preliminary set can be seen as a change of the electromyogram of the vocal tract.
} 


\section{A (re)criação no ouvir}

Relativamente a ouvir, retomando a terminologia de Emig (1977), também se associa o ato de (re)criar porquanto se gera a transposição de um input sonoro para o correlato conceptual que cada um possui dessa entrada na sua linguagem interior. Não admirará, pois, que cada pessoa "filtre" diferentemente o que ouve, posto que, ao processar o que lhe chega verbalmente, pode não gerar o mesmo tipo de (re)criação do input auditivo, porque se estima que sejam distintas as linguagens interiores individuais. Não se poderá, em consequência disso, afirmar que uma pessoa, no papel de ouvinte, se encontra em uma atitude passiva e em um modo offline. Aliás, importa frisar que, por força da diversidade de linguagens interiores, nem todos os membros de um grupo compreendem uma mensagem que lhes é dada a ouvir de modo idêntico. A situação de sala de aula poderá ser disso um bom exemplo. Seria uma pura ilusão acreditar-se que todos os alunos ouvem/compreendem no mesmo grau o que lhes é transmitido, visto que nem todos possuem na sua linguagem interior o correspondente exato do que lhes é dado a ouvir para que possam executar a transposição/ recriação almejada. Afinal, não se pode presumir que todos possuem conhecimentos que os capacitem a assimilar devidamente a informação que lhes vai chegando. No entanto, existem aqueles que, no seu laborioso silêncio de meros recetores, atingem cabalmente os objetivos fixados pelo emissor revelando-se, dessa forma, o que McLaughlin designa por "active listeners" ("ouvintes ativos") (1992, p.10). Sobressai desta expressão de McLaughlin o que ouvir representa de trabalho latente; isto é: o que pressupõe de labor psicolinguístico o ato de compreender, de agarrar o que é proferido em função do existente, reclamando sempre que o ouvinte esteja no modo online, ou seja, assuma uma atitude incompatível com passividade.

\section{O papel do input verbal nos processos verbais ouvir e ler}

O efeito da qualidade e da quantidade de input verbal a que o ser humano está exposto é por conseguinte de suma relevância, já que converge para nutrir a sua linguagem interior e conferir-lhe uma capacidade mais efetiva de assimilação informativa.

No que concerne às crianças, Sinclair (1974, p. 5), com a clareza de pensamento que lhe era tão peculiar, declara: "Além disso, o input deve ser em quantidade e de qualidade suficientes: uma criança a quem só se fala raramente ou que só ouça a sua língua mergulhada em ruído (rádio, televisão, etc.) não a poderá aprender corretamente."14 Prossegue, no entanto, afirmando que não se conhece o grau de input estimado suficiente, dado que também não existem meios para o medir.

$\mathrm{O}$ input verbal a que algumas crianças estão expostas pode ser mesmo muito reduzido, levando a que se questione como conseguem acompanhar e descodificar uma conversa. Para que possam compreender o que ouvem, valer-lhes-á o contexto, de toda a ordem, que integra o nível contextual da comunicação (SLAMA-CAZACU, 2007); no entanto, um contexto desnudado de elementos de ordem linguística não beneficiará infelizmente o enriquecimento da sua linguagem. Contribuirá, todavia, esse contexto para que se possa considerar a compreensão em um sentido lato, ou seja, não exclusivamente dependente de pontos de referência só linguísticos, como acontece na compreensão em sentido estrito. Essa última compreensão é a que ocorre em situações experimentais despidas de elementos extralinguísticos, paralinguísticos e discursivos a fim de os investigadores obterem respostas dos seus sujeitos que se coadunem com o seu saber exclusivamente linguístico de uma dada estrutura que pretendam estudar. A efetivação desta distinção de compreensões (lata e estrita) permite que através da estrita, ainda que se caracterize por uma certa artificialidade, se estude a compreensão, por exemplo, de conectores, que podem ser usados na linguagem com base unicamente em um conhecimento figurativo, recorrendo mais à imitação do modelo a que o sujeito está exposto, e não em um conhecimento operativo, se bem que o conhecimento figurativo se firme também no operativo (FURTH, 1981).

Vygotsky (1977, p. 87) anota que a criança pode usar, por exemplo, "porque" corretamente no discurso espontâneo, mas não saber como empregá-lo de modo deliberado. Por seu turno, Mitchell (1948) partilha com o leitor uma visão interessante da utilização frequente de "porquê?" pela criança que faz pensar que ela está simplesmente a ativar o mecanismo da assimilação funcional. São da autora as seguintes palavras:

Muitas vezes estamos tentados a dar-lhe razões em resposta ao seu incessante "porquê?" mas quando ele pergunta "porquê?" ele não está realmente à procura de qualquer razão. Grande parte do tempo ele nem está sequer a fazer uma pergunta. Ele sente unicamente prazer nesta forma verbal e fica indignado se a resposta que se lhe der não for a que ele espera [...] As suas perguntas tinham uma atitude social e não científica (MITCHELL, 1948, p. 9). ${ }^{15}$

\footnotetext{
${ }^{14}$ Do original: "En outre, l'input doit être de quantité et de qualité suffisantes: un enfant à qui l'on ne parle que rarement, ou qui n'entend sa langue que noyée dans du bruit (radio, télévision etc.) ne pourra pas l'apprendre correctement".

${ }^{15}$ Do original: Often we are tempted to give him reasons in response to his incessant "why?" but when he asks "why?" he really is not searching for reasons at all. A large part of the time he is not even asking a question. $\mathrm{He}$ merely enjoys this reciperative form of speech and is indignant if your answer is not what he expects [...] His questions had a social but not scientific bearing (MITCHELL, 1948, p. 9).
} 
A compreensão está tanto ao serviço do processo verbal ouvir, como do processo verbal leitura. Tem, no entanto, todo o cabimento ressaltar a diferença de inputs que se encontram por regra ao serviço dos dois processos convocados. A leitura serve-se da escrita, que é tida consensualmente como descontextualizada, e o ouvir serve-se da fala que, por natureza, é contextualizada. Não é difícil inferir do que acaba de ser apresentado que o processo verbal ler deve ser praticado, direta ou indiretamente, para que a compreensão por via do ouvir se preste a qualquer exemplar de género textual que possa ser concretizado por meio da fala (MARCUSCHI, 2001).

Será mesmo o contexto que acompanha o ouvir e que origina a compreensão em sentido lato que gera a posição tradicional que aponta para a compreensão verbal preceder a produção, se estiver em causa, por exemplo, um dado tipo de estrutura (PINTO, 1988).

Graciliano Ramos (2017), no seu livro Vidas secas, retrata bem a pobreza do discurso no seio de determinadas famílias quando os adultos conversam entre si e faz-nos perceber não só como se torna difícil a aquisição de uma linguagem mais elaborada por parte das crianças que a elas pertencem, mas também como os parcos recursos verbais podem explicar a razão da elevação do volume da voz em certas situações. Lê-se, então, nesse livro:

\begin{abstract}
A família estava reunida em torno do fogo. [...] As brasas estalaram, a cinza caiu, um círculo de luz espalhou-se em redor da trempe de pedra, clareando vagamente os pés do vaqueiro, os joelhos da mulher e os meninos deitados. De quando em quando, estes se mexiam, porque o lume era fraco e apenas aquecia pedaços deles. Outros pedaços esfriavam recebendo $o$ ar que entrava pelas rachaduras das paredes e pelas gretas da janela. Por isso não podiam dormir. Quando iam pegando no sono, arrepiavam-se, tinham precisão de virar-se, chegavam à trempe e ouviam a conversa dos pais. Não era propriamente conversa: eram frases soltas, espaçadas, com repetições e incongruências. Às vezes uma interjeição gutural dava energia ao discurso ambíguo. Na verdade, nenhum deles prestava atenção às palavras do outro: iam exibindo as imagens que lhes vinham ao espírito, e as imagens sucediam-se, deformavam-se, não havia meio de dominá-las. Como os recursos de expressão eram minguados, tentavam remediar a deficiência falando alto (2017, p. 63-64).
\end{abstract}

Interessa observar como Graciliano Ramos faz alusão, de uma maneira seminal, às frases soltas, às pausas que as medeiam, à redundância adveniente das repetições e a tantos outros artifícios que ajudam a alinhar um discurso pobre em palavras. Ignora-se se um estudioso da matéria o teria feito com o mesmo grau de minudência. Em resumo: tal discurso, retratando um input demasiado despojado dos meios verbais imprescindíveis à devida compreensão verbal, não contribuirá com certeza para a constituição de um output minimamente aceitável. Um output não reverbera obrigatoriamente o input; porém, apesar de não existir uma relação isomórfica entre o input e o output, o que ocorre no output tem de ter estado inevitavelmente presente em algum exemplar de input para que possa vir a figurar no output, depois de lhe ter sido prestada a atenção necessária, imprescindível ao seu surgimento.

Mais: o autor de Vidas Secas recorre às imagens que poderão ou não vir à mente associadas às palavras que vão sendo articuladas, imagens essas que, quantas vezes, desconfiguram tudo e fazem com que o que é ouvido seja transportado para uma esfera de significado bem distante da esperada. A menção às imagens tal como se lê em Graciliano Ramos é passível de ser associada a uma assimilação selvagem, tirando partido da terminologia conhecida sobretudo pelos que se dedicaram ao estudo da obra de Piaget, nomeadamente do livro Le langage et la pensée chez l'enfant, dado à estampa no início dos anos vinte do século pretérito. Quem o tiver feito recorda-se seguramente do fenómeno do sincretismo, que se traduz na propensão que a criança manifesta, face, por exemplo, a qualquer material verbal - na situação concreta provérbios e frases que os poderiam explicar -, para agregar em um todo confuso uma série de ideias separadas (GINSBURG; OPPER, 1979, PIAGET, 1976). $\mathrm{O}$ que acaba de ser redigido justifica a necessidade de se ter presente que o processo verbal ouvir envolve compreender e de se chamar a atenção para a divergência que se pode verificar na compreensão de qualquer input verbal em razão do que se encontra armazenado no léxico mental de cada um. Desta forma, fica claro que o ouvinte só pode estar online quando cria ou recria, ao sabor das suas capacidades e dos seus hábitos verbais, podendo, por efeito disso, cometer vacilações em matéria de rigor diante dos mais variados inputs ou chegar a interpretações incongruentes relativamente ao que seria de aguardar.

\section{Apontamento final}

O trajeto que este texto ostenta, fruto quer da intenção do seu autor, quer das forças inerentes aos conceitos nele constantes, manifesta uma vontade de contemplar a leitura de diferentes ângulos e de jogar com o muito que uma abordagem psicolinguística de uma dada matéria desvela a quem a seguir.

Os processos verbais ler e ouvir foram versados neste texto com a intenção de mostrar como contêm aspetos em comum e como, malgrado alguns rótulos que lhes são atribuídos na direção de uma passividade com que não se devem identificar, terão de ser vistos como processos de onde jorra uma atividade psicolinguística intensa. 
Mostrou-se como a compreensão podia ser um denominador comum a ouvir e a ler e de que forma esse ponto de encontro - a capacidade de compreensão - pode ser a causa de divergências de desempenho.

Não se poupou o recurso a citações que defendiam cirurgicamente a matéria que ia sendo explanada, com o intento de conferir-lhe a devida credibilidade. Sublinhese o potencial que encerram o pensamento de Agostinho da Silva e o trecho de Graciliano Ramos, escritores com formações que, em princípio, se distanciarão da dos restantes autores mencionados.

Apelou-se ainda para a conveniência de se ter bem presente a dinâmica que emerge das dicotomias, em resultado de se terem elencado algumas, de sorte que da apreciação dessa força se possa ver brotar não uma incompatibilidade entre as dimensões de qualquer uma delas, mas antes a sua complementaridade funcional.

Deixa-se, finalmente, como recado a urgência de trabalhar a linguagem nas suas diversas facetas, com objetivas diversas que convirjam em um olhar plural, e de não ficar nunca pela periferia de qualquer processo verbal (oral ou escrito), sob pena de se perder o que de crucial contêm os que foram enunciados (ouvir, falar, ler, escrever), quando, porque é importante ir à sua raiz, se objetiva investigar e explicar, recorrendo à imprescindível problematização, como se desencadeia o processamento dos aduzidos processos.

\section{Referências}

BISAILLON, Jocelyne. Professional editing strategies used by six editors. Written Communication, [s. l.], v. 24, n. 4, p. 295-322, 2007. https://doi.org/10.1177/074108830 7305977

ELKONIN, Daniil B. How to teach children to read. In: DOWNING, John A. (ed.). Cognitive psychology and reading in the U.S.S.R. Amsterdam: Elsevier, 1988. p.387-426. https://doi.org/10.1016/S0166-4115(08)60389-1

ELLIS, Rod. The study of second language acquisition. Oxford: Oxford University Press, 1994.

EMIG, Janet. Writing as a mode of learning. College Composition and Communication, Urbana, v. 28, n. 2, p. 122-128, 1977. https://doi.org/10.2307/356095

FURTH, Hans G. Piaget \& knowledge: theoretical foundations. 2nd ed. Chicago: The University of Chicago Press, 1981.

GINSBURG, Herbert; OPPER, Sylvia. Piaget's theory of intelectual development. 2nd ed. Englewood Cliffs: Prentice-Hall, 1979.

GIROLAMI-BOULINIER, Andrée. L'apprentissage de l'oral et de l'écrit. Paris: PUF, 1993. (Que sais-je?, n. 2717).
GIROLAMI-BOULINIER, Andrée. Les premiers pas scolaires: acquisitions indispensables pour prévenir l'échec scolaire. Issy-les-Mloulineaux: Editions et Applications Psychologiques, 1988.

GOLDMAN EISLER, Frieda. Psycholinguisitcs: experiments in spontaneous speech. London: Academic Press, 1968.

HOWARD, David; HATFIELD, Frances M. Aphasia therapy: historical and contemporary issues. Hove: Lawrence Erlbaum Associates, 1987.

LURIA, Alexander R. The pathology of grammatical operations. In: DOWNING, John A. (ed.). Cognitive psychology and reading in the U.S.S.R. Amsterdam: Elsevier, 1988. p. 95-141. https://doi.org/10.1016/S01664115(08)60372-6

LURIA, Alexander R.; TSVETKOVA, Lubov S. The mechanism of 'dynamic afasia'. Foundations of Language, [s. l.], v. 4, n. 3, p. 296-307, Aug. 1968.

MARCUSCHI, Luís Antônio. Da fala para a escrita: atividades de retextualização. 2. ed. São Paulo: Cortez, 2001.

MCLAUGHLIN, Barry. Myths and misconceptions about second language learning: what every teacher needs to unlearn. Santa Cruz: University of California, 1992. (Educational Practice Report, 5).

MARSHALL, John; NEWCOMBE, Freda. Patterns of paralexia: a psycholinguistic appraoch. Journal of Psycholinguistic Research, New York, v. 2, n 3, p. 175-199, 1973. https://doi.org/10.1007/BF01067101

MITCHELL, Lucy Sprague. Here and now story book. New York: E. P. Dutton \& Company, 1948. Disponível em: http://www.gutenberg.org/files/27075/27075-h/27075-h.htm. Acesso em: 27 out. 2018.

MORTON, John; PATTERSON, Karalyn. A new attempt at an interpretation, or, an attempt at a new interpretation. In: COLTHEART, Max; PATTERSON, Karalyn; MARSHALL, John C. (ed.). Deep dyslexia. London: Routledge \& Kegan Paul, 1980. p. 91-118.

ODISHO, Edward Y. A multisensory, multicognitive approach to teaching pronunciation. Linguística: Revista de Estudos Linguísticos da Universidade do Porto, Porto, v. 2, p. 3-28, 2007.

PIAGET, Jean. Le langage et la pensée chez l'enfant. Neuvième édition. Neuchâtel: Delachaux et Niestlé, 1976.

PINTO, Maria da Graça Lisboa Castro. Abordagem a alguns aspetos da compreensão verbal na criança: estudo psicolinguístico genético do Token Test e de materiais de metodologia complementar. Lisboa: Instituto Nacional de Investigação Científica, 1988. https://doi.org/10.20873/ uft.2447-4266.2017v3n4p488 
PINTO, Maria da Graça Lisboa Castro. Da revisão na escrita: uma gestão exigente requerida pela relação entre leitor, autor e texto escrito. Revista Observatório, Palmas, v. 3, n. 4, p. 488-517, jul./set. 2017 b.

PINTO, Maria da Graça Lisboa Castro. Nos bastidores da iniciação à entrada no mundo da escrita: do CALE a intervenções e pressupostos de ordem cognitiva e neurológica. Porto: Faculdade de Letras da Universidade do Porto e Centro de Linguística da Universidade do Porto, 2017a.

RAMÍREZ GÓMEZ, Danya. Language teaching and the older adult: the significance of experience. Bristol: Multilingual Matters, 2016. https://doi.org/10.21832/ 9781783096305

RAMOS, Graciliano. Vidas secas. 135. ed. São Paulo: Record, 2017.

SINCLAIR, Hermina J. L'acquisition du langage d'un point de vue Piiagetien. Folia Phoniatrica, Basel, v. 26, p. 1-12, 1974. https://doi.org/10.1159/000263764

SLAMA-CAZACU, Tatiana. Psicolingüística aplicada ao ensino de línguas. São Paulo: Livraria Pioneira, 1979.

SLAMA-CAZACU, Tatiana. Psycholinguistics, where to in the 21 st century? In: ARABSKI, Janusz (ed.). Challenging tasks for psycholinguisitcs in the new century. Katowice: University of Silesia, 2007. p. 77-85.

STANOVICH, Keith E. Matthew effects in reading: some consequences of individual differences in the acquisition of literacy. Reading Research Quarterly, Newark, v. 21, p. 360-407, 1986. https://doi.org/10.1598/RRQ.21.4.1

STANOVICH, Keith E. Progress in understanding reading: scientific foundations and new frontiers. New York: The Guilford, 2000.

TEMPLE, Christine M. Developmental analogues to acquired phonological dyslexia. In: MALATESHA, R. N.; WHITAKER, Harris A. (ed.). Dyslexia: a global issue. The Hague: Martinus Nijhoff Publishers, 1984. p. 143-158. https://doi.org/10.1007/978-94-009-6929-2_8

TEMPLE, Christine M. Reading with partial phonology: developmental phonological dyslexia. Journal of Psycholinguistic Research, New York, v. 14, n. 6, p. 523-541, 1985b. https://doi.org/10.1007/BF01067383

TEMPLE, Christine M. Surface dyslexia: variations within a syndrome. In: PATTERSON, Karalyn E.; MARSHALL, John C.; COLTHEART, Max (ed.). Neurospychological and cognitive studies of phonological reading. London: Lawrence Erlbaum Associates, 1985a. p. 269-288. https://doi. org/10.4324/9781315108346-16

VYGOTSKY, Lev S. Thought and language. Cambridge: MIT Press, 1977.
Recebido em: 13/6/2019. Aprovado em: 24/6/2019. Publicado em: 5/11/2019.

\section{Autora:}

Maria da Graça Pinto

Título de Agregada em Línguas e Literaturas Românicas, pela

Universidade do Porto (UP), Porto, Portugal.

Orcid: https://orcid.org/0000-0002-4842-991X

E-mail:mglcpinto@gmail.com

Endereço: Universidade do Porto

Faculdade de Letras

Via Panorâmica s/n. - Massarelos

4150564, Porto, Portugal 